\title{
The role of code-switching and language context in bilingual phonetic transfer
}

\author{
Daniel J. Olson
}

Purdue University

danielolson@purdue.edu

The present study examines the effect of two potential catalysts for interlanguage phonetic interaction, code-switching and language mode, on the production of voice onset time (VOT) to better understand the role of (near) simultaneous dual language activation on phonetic production, as well as the nature of phonetic transfer. An oral production paradigm was carried out in which Spanish-English bilinguals produced words with initial voiceless stops as non-switched tokens, code-switched tokens in an otherwise monolingual context, and code-switched tokens in a bilingual context. Results demonstrated a degree of phonetic transfer associated with code-switching, either unidirectional or bi-directional. Specifically, English, with long lag VOT, was more susceptible to phonetic transfer than Spanish (short lag). Contrary to expectations, while the code-switching effect was present in both monolingual and bilingual mode, there was no additional transfer, or additive effect, of bilingual language mode. Differences in the effects of code-switching on English and Spanish are discussed with respect to the inherently different acceptable VOT ranges in the two languages. Furthermore, the lack of difference in VOT between the code-switched tokens in the monolingual and bilingual contexts is taken to suggest limits on phonetic transfer.

\section{Introduction}

In storing two competing languages in one mind, bilinguals are consistently tasked with separating and selectively accessing their languages. While bilinguals are generally highly efficient at language separation, such separation does not preclude a degree of interlanguage interaction or dual activation (e.g. Blumenfeld \& Marian 2007). Moreover, this language selection, and potential interlanguage interaction, occurs for the various components of language, including the syntactic, lexical, and phonetic levels. The phonetic level, given the gradient nature of some phonetic features, may offer a fine-grained measure of such interlanguage interaction. Such interaction is possible when bilinguals operate in one of their languages; however, contexts involving nearly simultaneous use of both languages, such as code-switching or operating in a bilingual language mode, may serve as a catalyst for additional interlanguage phonetic interaction.

Among bilingual speech patterns, one of the most salient and well-studied phenomena is that of code-switching, broadly defined as the alternation between two (or more) languages or language varieties within a single interaction (Myers-Scotton 1993). Of the extant studies 
regarding the phonetic reflexes of code-switching, the outcomes of this potential source of interaction have been variable, including no phonetic interaction (Grosjean \& Miller 1994), unidirectional transfer (Bullock et al. 2006, Antoniou et al. 2011, Balukas \& Koops 2015), and bi-directional transfer (Bullock \& Toribio 2009), as well as some variation depending on the place of articulation (González López 2012). These findings have been shown for both early bilinguals (Balukas \& Koops 2015) as well as late bilinguals (Bullock et al. 2006, Bullock \& Toribio 2009, Gónzález Lopez 2012), the latter being the focus of the current study. Adding to this complex picture, language mode, or the relative position of a bilingual on a continuum from monolingual to bilingual speech patterns in a given conversation, has also been shown to have an effect on segmental phonetic production (Olson 2013, Simonet 2014). Moreover, the impact of language mode on segmental phonetic production has been shown for non-switched constituents, generally seen as a degree of phonetic transfer occurring in a more bilingual context relative to a monolingual context. Although both code-switching and language mode effectively serve as potential sources for interlanguage phonetic interaction (i.e. transfer), the potential interplay of these two variables has yet to be examined.

In light of the variable findings regarding the influence of code-switching on segmental production, and the potential additive role of a bilingual language mode, the current study examines the phonetic reflexes of code-switching and the role of language mode. Furthermore, given that both code-switching and bilingual language mode serve as potential catalysts for interlanguage interaction, this paradigm may provide some insights into the nature of, and potential limits on, phonetic transfer itself.

\section{Literature review}

A large body of literature has sought to demonstrate that, with respect to segmental phonetics, bilinguals are able to effectively maintain separate sets of phonetic norms in each of their two languages (Caramazza et al. 1973, Hazan \& Boulakia 1993, MacLeod \& Stoel-Gammon 2010). Some studies, particularly for highly proficient early bilinguals, have shown that bilinguals are capable of producing segmental features in line with those of the corresponding monolingual populations (Nathan, Anderson \& Budsayamongkon 1987, Mack 1989, Magloire \& Green 1999, Macleod \& Stoel-Gammon 2005). Other studies, however, have shown that, while maintaining different norms for their two languages, bilingual phonetic productions are not necessarily identical to monolingual norms (Flege \& Port 1981, Flege \& Hillenbrand 1984, Major 1987), with bilinguals generally showing some degree of convergence towards the opposite language norms (Caramazza et al. 1972; see Flege \& Eefting 1987, for both convergence and divergence). Although there is some debate regarding the underlying processes responsible for acquisition, the existence of dual phonetic systems holds for both early simultaneous bilingual acquisition (Unitary System Model, e.g. Volterra \& Taeschner 1978; Dual Systems Model, e.g. Keshavarz \& Ingram 2002), as well as late second language acquisition (Speech Learning Model, Flege 1995; Perceptual Assimilation Model-L2, Best \& Tyler 2007). Furthermore, bilinguals are able to distinguish two phonetic systems in both production and perception (e.g. Bosch \& Sebastian-Galles 2003). As such, there is a strong consensus that bilinguals effectively maintain, produce and perceive different phonetic systems for each of their two languages, albeit with some potential exceptions, particularly for very similar contrasts in a bilingual's two languages (Flege 1995, Pallier, Bosch \& Sebastian Galles 1997).

Although it is clear that bilinguals maintain two distinct systems, they are not necessarily autonomous. A large body of evidence has demonstrated that bilinguals generally experience a degree of dual or parallel activation during language activity (e.g. Ju \& Luce 2004), a phenomenon that occurs even in a monolingual setting (e.g. Marian \& Spivey 2003a, b). 
The degree of parallel activation, however, is dependent on a number of factors, including language proficiency (Weber \& Cutler 2004), cognate status (e.g. Blumenfeld \& Marian 2007) and language exposure (e.g. Spivey \& Marian 1999). As such, language selection mechanisms must effectively manage such parallel activation to ensure production of the correct language (see Kroll \& Stewart 1994, Green 1998, among others).

Unlike dual systems at the lexical and syntactic levels, where contrasting lexical items or syntactic structures are often categorically representative of one language or the other, the gradient nature of the phonetic system allows for a fine-grained measure of the type and degree of interlanguage interaction. Such interlanguage phonetic interaction has been observed in non-switched interaction and during acquisition (Caramazza et al. 1973, Flege, Mackay \& Piske 2002, Kehoe, Lleó \& Rakow 2004, Fowler et al. 2008). However, the fundamental nature of, as well as the extent or limitations on, such interaction is not clear (e.g. FabianoSmith \& Barlow 2010). While phonetic interaction may occur in non-switched productions, for example, as seen in the difference between bilingual and monolingual speakers' phonetic norms when using a single language (e.g. Caramazza et al. 1973), contexts that employ both of a bilingual's two languages, such as code-switching and/or bilingual language mode, may serve as catalysts for interaction. As such, code-switching and language mode may present a unique opportunity to better understand this interlanguage phonetic interaction.

\subsection{Code-switching and phonetic interaction}

Of primary interest in the study of the segmental phonetics of code-switching has been the question of whether interaction occurs between a bilingual's two phonetic systems as the result of code-switching, and if so, what type of interlanguage phonetic interaction occurs. As a point of departure, researchers have sought evidence of phonetic transfer at (or near to) the point of a code-switch, when the segmental phonetic production of one language shifts in the direction of the phonetic norms of the other language. This phonetic interaction between the two systems could potentially be unidirectional, with only Language A influencing Language B, or bi-directional, with Languages A and B exerting mutual influence. Conversely, it is possible that code-switching does not serve as a source of interlanguage phonetic interaction, and code-switched tokens may be produced with no discernable difference from a given speaker's non-switched norms.

To examine this issue, researchers have most commonly exploited differences in voice onset time (VOT). VOT, defined as the lag between the release of the closure of a stop consonant and the subsequent onset of voicing, has traditionally been used as a principal (although not sole) marker of the distinction between voiced and voiceless stops (Lisker \& Abramson 1964). As VOT has been shown to differ cross-linguistically, languages with a bipartite system can be generally classified as having either long lag or short lag voiceless stops. Long lag voiceless stops, in languages like English, have a VOT of approximately 30-120 ms. Short lag voiceless stops, in languages like Spanish and French, have a VOT of approximately 0-30 ms (e.g. Lisker \& Abramson 1964).

In one of the first studies designed to analyze the phonetic effects of code-switching, Grosjean \& Miller (1994) investigated the phonetic productions at the point of switch by exploiting the VOT difference between French (short lag) and English (long lag). Stimuli consisted of French utterances (MATRIX LANGUAGE), with single insertional English codeswitched tokens (EMBEDDED LANGUAGE), along with non-switched English and non-switched French control utterances. Results showed that there were no significant differences between the non-switched English and the code-switched English productions. With respect to the production of VOT at the point of switch, Grosjean \& Miller (1994: 203) concluded that, 'switching from one language to another appears to involve a total change, not only at the lexical level but also at the phonetic level'. However, as pointed out by Bullock \& Toribio (2009), the stimuli used by Grosjean \& Miller (1994) were all cross-linguistic homonyms and proper names, such as Carl, which were produced in both languages. The nature of these 
tokens may actually encourage participants to hyper-articulate the tokens to indicate that they pertain to the opposite language.

Although the findings reported by Grosjean \& Miller (1994) support a theory of a complete switch, they are seemingly outweighed by a number of studies that indicate some level of phonetic transfer. For example, Bullock et al. (2006) studied the phonetic reflexes of code-switches in late English-Spanish bilinguals, both English-dominant and Spanishdominant, and found a degree of unidirectional transfer. Again, exploiting the long lag/short lag (English/Spanish) distinction, the results indicated that transfer was dependent on the direction of switch (English to Spanish vs. Spanish to English). When switching from Spanish to English, both English- and Spanish-dominant speakers produced code-switched English tokens with significantly shorter, more 'Spanish-like' VOTs. In contrast, neither group evidenced phonetic transfer when switching from English to Spanish. It is worth noting that there was an effect pre-switch, such that English-dominant speakers produced significantly shorter Spanish VOTs in the pre-switch position than in the non-switched condition. Similarly, Antoniou et al. (2011) investigated the VOT of code-switched tokens in Greek-English L2dominant (English) bilinguals. Again, the experimental design paired a long lag (English) and short lag (Greek) language. In a similar procedure, although using Greek and English pseudo-words, results indicated unidirectional transfer (i.e. short lag to long lag), with Greek phonetic norms influencing code-switched English tokens.

These findings of unidirectional transfer, most notably short lag to long lag languages, have come from carefully controlled laboratory speech tasks, yet more recent work has found a similar pattern in naturalistic speech of Spanish-English early sequential bilinguals (Balukas \& Koops 2015). In their examination of conversational New Mexican Spanish, Balukas \& Koops (2015) found that at the point of code-switching or shortly thereafter, English tokens were produced with significantly shorter VOT (i.e. more Spanish-like) than non-switched tokens. However, Spanish tokens demonstrated no impact of code-switching on phonetic production.

Also supporting findings of a degree of phonetic interaction, albeit bi-directional transfer, Bullock \& Toribio (2009) analyzed VOT in three groups of Spanish-English bilinguals in a laboratory speech task. Findings for late English- and Spanish-dominant bilinguals parallel the unidirectional transfer found in a number of other studies. Early bilinguals, however, demonstrated bi-directional transfer, with English VOTs becoming more Spanish-like at the point of switch, and Spanish VOTs becoming more English-like. Importantly, in addition to providing evidence of bi-directional transfer, these results suggest that Spanish, a short lag language, is not impervious to transfer. Drawing on spontaneous speech, Piccinini \& Arvaniti (2015) also found that both English and Spanish incurred a shift in VOT at the point of codeswitch. Worth noting, while English VOT was influenced in the predicted manner (i.e. shorter VOT), Spanish code-switched VOTs actually were SHORTER than non-switched tokens.

Taken as a whole, these studies suggest that code-switching is most often associated with a degree of interlanguage phonetic interaction, namely unidirectional transfer. Importantly, this transfer can most often be characterized as short to long lag transfer, in which code-switching effectively shortens the VOT produced in a long lag language. Bullock et al. (2006: 14) suggest that this degree of unidirectional transfer may result from 'inherent differences between the languages'. Specifically, English allows for a greater range of acceptable VOTs, which allows 'room' for VOTs to shift, whereas the range of Spanish VOTs is more constrained and thus more resistant to transfer.

\subsection{Language context and phonetic interaction}

In daily activities, bilinguals must consistently decide which language to use, if code-switching is conversationally appropriate, and how much switching should be employed. These differing degrees of bilingual operation, referred to as LANGUAGE MODES, can be described as a continuum from monolingual speech (Language A) to bilingual speech (Languages A and 
B) to monolingual speech (Language B) (e.g. Grosjean 2001). That is, while bilinguals can effectively converse in either of their two languages, representative of a MONOLINGUAL LANGUAGE MODE, they can also operate bilingually, a phenomenon known as BILINGUAL MODE. The idea of language mode has been further refined, namely through the work of Grosjean (Grosjean 1982, 2001, 2008; Soares \& Grosjean 1984) to include both written and oral speech (Grosjean 1997), as well as production and perception (Grosjean 1998). It is important to note, language mode has been discussed in terms of the relative levels of activation of Language A to Language B (Grosjean 2008). When operating in monolingual mode, dual activation is minimal, although not non-existent. In a truly bilingual mode, both languages receive similar levels of activation, essentially maximizing the dual/parallel activation.

While language mode may be manipulated by a host of social and psychological factors in naturalistic speech, in an experimental setting, language mode may be induced by adjusting the LANGUAGE CONTEXT, or the relative quantity of each language present in a given discourse. Grosjean (2008) notes that inducing a purely monolingual mode in an experimental setting may prove impossible, as can be seen in experimental work on bilingual language perception (e.g. Blumenfeld \& Marian 2007); however, the position of a speaker along the language mode continuum, excluding monolingual endpoints, may be experimentally manipulated.

While code-switching represents a local point in speech production in which both languages are accessible, and thus serves as a catalyst for interlanguage interaction, bilingual language mode represents a more global context for some degree of dual language accessibility. As such, bilingual language mode also presents an opportunity for interlanguage interaction. A number of authors have demonstrated that adjusting the language mode or language context has a direct impact on production, particularly at the phonetic level. For example, Simonet (2014) demonstrated an effect of language context on vowel production in Catalan-Spanish bilinguals. Specifically, there was a significant difference in vowel height for Catalan mid vowels when produced in a unilingual session (i.e. only Catalan) when compared to vowels produced in a bilingual session, with both Catalan and Spanish utterances. Crucially, the tokens analyzed by Simonet (2014) were NOT code-switched tokens; rather the bilingual context consisted of full utterances from each language. As such, the interlanguage phonetic interaction found can be attributed not to a local point of dual activation (i.e. code-switching), but rather to the presence of both languages in the experimental setting (i.e. bilingual language context).

Similar impacts of language context on phonetic production have also been attested in other experimental paradigms. Olson (2013), for example, presented picture stimuli in a cued language-switching paradigm in either more monolingual contexts (i.e. 95\% English, 5\% Spanish) or more bilingual contexts (i.e. 50\% English, 50\% Spanish) and found differing impacts of language switching and a difference in NON-SWITCHED tokens with respect to VOT in the two contexts. Importantly, non-switched tokens produced in bilingual contexts evidenced a degree of phonetic transfer. VOT for English tokens shifted in the direction of Spanish norms in the bilingual context relative to the monolingual context. A corresponding shift, towards English norms, was also found for Spanish tokens. The findings for nonswitched tokens were taken as support for global effects (i.e. language context), while the impact of language switching was seen as indicative of local effects.

Considering the previous research, it is clear that the variable of language mode has an impact on phonetic production. Generally, these studies have produced evidence of the potential for phonetic transfer resulting from bilingual language contexts or modes. Couched within a framework of activation or accessibility (e.g. Grosjean 2008), operation in a monolingual mode corresponds to a maximal activation for Language A and minimal activation for the competing Language $\mathrm{B}$. When operating in a more bilingual language mode, Languages A and B receive relatively equal levels of activation. As such, bilingual language contexts represent a source for interlanguage interaction, potentially explained by a sort of 
dual activation or equal accessibility of both sets of language norms and evidenced at the phonetic level by phonetic transfer, as described above.

\subsection{Research questions}

Drawing on the previous research, it is clear that when bilinguals use both languages simultaneously, or nearly simultaneously, there is a potential for interlanguage interaction. Such interlanguage interaction, often evidenced by phonetic transfer, may be driven by either local points of dual language activation (i.e. code-switching) or a more global dual activation (i.e. bilingual language context). Namely, code-switching has been shown to induce phonetic interaction, specifically phonetic transfer, either unidirectionally or bi-directionally. In addition, language context has also been shown to be a source of transfer, with phonetic transfer occurring in productions in a bilingual language context.

Given these two sources of phonetic transfer, the research questions addressed in this work are:

RQ1: Seeking to clarify previously variable results, does code-switching impact segmental production, either through unidirectional or bi-directional transfer, as evidenced by voice onset time?

Hypothesis: Drawing on the previous literature (Antoniou et al. 2011, Bullock et al. 2006, Bullock \& Toribio 2009), it is anticipated that code-switching will impact phonetic production. Furthermore, although bi-directional transfer is possible (e.g. Bullock \& Toribio 2009), at minimum unidirectional transfer of the short lag language to the long lag language (e.g. Spanish to English) is expected.

RQ2: Is there a cumulative impact of both bilingual language mode and code-switching on segmental production, as evidenced by voice onset time?

Hypothesis: Given that both code-switching (e.g. Bullock \& Toribio 2009) and bilingual language mode (e.g. Olson 2013, Simonet 2014) have been shown to be catalysts for phonetic transfer, it is anticipated that they will have a cumulative impact. That is, it is expected that code-switching in a bilingual context will induce a greater degree of phonetic transfer than code-switching in a monolingual context.

\section{Method}

To investigate the research questions detailed in Section 2.3 above, an oral production task was administered to Spanish-English bilinguals, both Spanish-dominant and English-dominant. Participants produced tokens in three conditions, further detailed below: as non-switched tokens and code-switched tokens in a monolingual context, as well as code-switched tokens in a bilingual context. To analyze the impact of language dominance, response language was balanced, and tokens were produced in both the L1 and L2 in each of the above conditions. Tokens were analyzed with respect to voice onset time.

\subsection{Participants}

Fourteen English-Spanish bilingual volunteers were recruited from The University of Texas at Austin and surrounding community. One subject (Spanish-dominant) was eliminated for failing to complete all parts of the task. Each participant's language background was assessed using a modified version of the LEAP-Q (Marian, Blumenfeld \& Kaushanskaya 2007) and relied on self-ratings, which have been shown to be an accurate representations of linguistic performance in bilingual speakers (Chincotta \& Underwood 1998, Flege, Yeni-Komshian \& 
Liu 1999, Jia, Aaronson \& Wu 2002). The language background questionnaires were prepared in both English and Spanish, and participants were free to choose their preferred version. The language background questionnaire was administered during the first session by a bilingual experimenter.

English-dominant participants $(n=7)$, having learned English as an L1 and Spanish after the age of 12, self-rated their English as significantly stronger than Spanish in both speaking $(t(6)=7.07, p<.001)$ and comprehension $(t(6)=7.78, p<.001)$. Spanishdominant participants $(n=6)$, learned Spanish as an L1 and English after the age of 12 and self-rated their Spanish as stronger than English in both speaking $(t(5)=5.94, p=.002)$ and comprehension $(t(5)=6.71, p=.001)$. Similar trends were also found, again via self-reporting on the language background questionnaire, for current daily exposure, self-perceived accent, and other-perceived accent, with all speakers demonstrating greater use and less accent in their L1 relative to their L2. English-dominant participants were all born and raised in the U.S., although they had all spent time in various Spanish-dominant environments. Spanishdominant participants were all born and raised in various Spanish-dominant environments, mainly Latin America, and had spent time in the U.S. (see Appendix A). While different dialects of Spanish have been shown to vary somewhat with respect to VOT (e.g. Williams 1977), they consistently fall within the short lag range. ${ }^{1}$

Lastly, given that not all bilinguals engage in code-switching, participants were asked to evaluate their code-switching habits. Both groups of speakers reported switching languages with similar frequency $(t(13)=-1.41, p=.188)$ and were equally comfortable when others switch languages $(t(13)=1.56, p=.15)$. All participants reported normal speech and hearing. Table 1 summarizes the language backgrounds of both groups.

Table 1 Language experience and proficiency questionnaire results. The numbers in parentheses indicate standard deviations.

\begin{tabular}{|c|c|c|c|c|c|c|c|c|}
\hline \multirow[b]{2}{*}{ Language background } & \multicolumn{3}{|c|}{ Age of acquisition } & \multicolumn{3}{|c|}{ English proficiency ${ }^{\mathrm{a}}$} & \multicolumn{2}{|c|}{ Spanish proficiency ${ }^{\mathrm{a}}$} \\
\hline & \multicolumn{2}{|c|}{ English } & Spanish & Speaking & \multicolumn{2}{|c|}{ Comprehension } & Speaking & Comprehension \\
\hline English-dominant & \multicolumn{2}{|c|}{$0.0(0.0)$} & $15.3(4.9)$ & $9.0(0.0)$ & \multicolumn{2}{|c|}{$9.0(0.0)$} & $6.1(1.1)$ & $7.3(0.5)$ \\
\hline \multirow[t]{2}{*}{ Spanish-dominant } & \multicolumn{2}{|c|}{$12.8(1.3)$} & $0.0(0.0)$ & $6.0(1.1)$ & \multicolumn{2}{|c|}{$7.3(0.8)$} & $8.8(0.4)$ & $8.8(0.4)$ \\
\hline & \multicolumn{2}{|c|}{ Current daily usage $^{\text {b }}$} & \multicolumn{2}{|c|}{ Self-perceived accent ${ }^{\natural}$} & \multicolumn{2}{|c|}{ Other -perceived accent ${ }^{d}$} & \multicolumn{2}{|c|}{ Language switching } \\
\hline Language background & Exposed & Speak & English & Spanish & English & Spanish & Self switching ${ }^{e}$ & Other switching ${ }^{\dagger}$ \\
\hline English-dominant & $3.6(1.6)$ & $3.10(1.5)$ & $9.0(0.0)$ & $5.4(1.6)$ & $1.0(0.0)$ & $7.0(2.1)$ & $5.9(2.3)$ & $7.7(1.3)$ \\
\hline Spanish-dominant & $5.2(1.6)$ & $6.16(1.4)$ & $3.7(1.0)$ & $8.8(0.4)$ & $8.2(1.1)$ & $1.0(0.0)$ & $7.5(1.9)$ & $6.8(0.8)$ \\
\hline
\end{tabular}

${ }^{a}$ Likert scale $1-9(1=$ don't understand; $9=$ native speaker $)$

${ }^{b}$ Likert scale $1-9(1=$ only English; $9=$ only Spanish $)$

${ }^{\circ}$ Likert scale $1-9(1=$ very heavy accent; $9=$ no accent $)$

${ }^{d}$ Likert scale $1-9(1=$ never perceived as non-native; $9=$ always perceived as non-native $)$

${ }^{\mathrm{e}}$ Likert scale $1-9(1=$ never switch; $9=$ frequently switch $)$

${ }^{\dagger}$ Likert scale $1-9(1=$ confusing when others switch; $9=$ seems normal when others switch $)$

\subsection{Stimuli}

Stimuli consisted of a contextualizing paragraph, followed by a contrastive focus utterance containing the post-focal target token with a voiceless stop consonant in initial position. The stimuli contained target tokens in both English and Spanish, produced in three distinct conditions: (i) Monolingual Context - Non-switched, non-switched target token in a monolingual context; (ii) Monolingual Context-Code-switched, code-switched target token in a monolingual context; and (iii) Bilingual Context - Code-switched, code-switched target

${ }^{1}$ In the current study, individual variation in VOT is also to be accounted for statistically, by including Subject as a random effect in the mixed effect model. 
token in a bilingual context. The examples in $(1 \mathrm{a}-\mathrm{c})$ illustrate the resulting three stimuli types, with the target English token indicated in italics (for translations see Appendix B). Corresponding stimuli were created with the opposite language pairings (Appendix C). All stimuli were evaluated by an early balanced Spanish-English bilingual for grammatical acceptability. The target tokens and contextualizing paragraph are further detailed below.

(1) a. Monolingual Context-Non-switched

I went to my daughter's school, because I had a meeting about her behavior, but I went to the wrong classroom.

The nice lady smiled, and said "No, not me. MS. HARRISON AND MRS. SMITH are the teachers in charge of your daughter's class."

b. Monolingual Context - Code-switched

Salió un reportaje sobre la gente que trabaja en las escuelas públicas.

Mi madre me preguntó, "¿Tu escuela tiene buena gente?”

"¿Mi escuela? No, pero la escuela de mi HERMANA tiene teachers muy buenos que enseñan a los niños."

c. Bilingual Context-Code-switched

My parents wanted the escuela with the best people to educate me.

"La escuela pública tiene los mejores?" my mom asked.

"No, la PRIVADA tiene teachers muy buenos en cada clase," my dad told her.

\subsubsection{Target tokens}

Target words in both English and Spanish consisted of an initial CV structure, balanced for

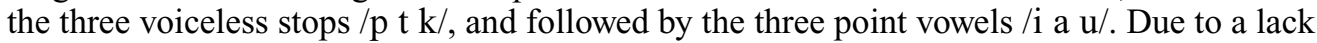
of Spanish words fitting the strict target criteria, there were only two tokens beginning with $/ \mathrm{ki}$ / in Spanish. Target tokens in both English and Spanish were non-cognate (de Groot 1992), two-syllable words with word-initial lexical stress. In total, there were 27 English and 26 Spanish tokens. All target tokens were nouns and consisted of single-word lexical insertions in the code-switched conditions (for a review of the frequency of single N/NP insertions, see Chan 2003). In addition, target tokens were also normed for semantic predictability, further detailed in Olson (published online 4 February 2015). All tokens were shown to be highly semantically predictable.

A norming study was conducted to ensure that target tokens represented code-switches, not loanwords fully or partially adopted into the opposite language (Poplack \& Sankoff 1984). Seven early Spanish-English bilinguals (age of acquisition, English: $M=2.5$ years; Spanish: $M=0.0$ years), different from those in the oral production task, participated in the codeswitch norming task. Participants were provided with a list of 85 tokens (27 English targets, 26 Spanish targets, 32 non-target tokens) and rated via Likert scale how 'English-like' or 'Spanish-like' they considered each token ( $1=$ Only English, $10=$ Only Spanish). Nontarget tokens were chosen that would be potentially acceptable as part of both languages; these included cognates (e.g. doctor) and generally accepted loanwords adopted from English into the local variety of Texas Spanish (e.g. lonche 'lunch') and Spanish into English (e.g. tortilla).

Results of the norming study illustrated that English target tokens were rated as strongly English-like $(M=1.37, S D=1.10)$ and Spanish target tokens were rated as strongly Spanishlike $(M=9.34, S D=1.55)$. The non-target tokens, not used in the oral production experiment, were generally rated as being acceptable in both languages $(M=6.31, S D=2.68)$. Subsequent statistical analysis (ANOVA) demonstrated a significant effect of token type (English, Spanish, non-target) $(F(2,80)=238.3, p<.001)$ on ratings. A post-hoc analysis (TukeyHSD) revealed a significant difference between the English target tokens and the Spanish target tokens (diff. 7.97, $p<.001, d=5.93$ ), and both were shown to be significantly different from the non-target tokens (English: diff. $=4.95, p<.001, d=2.41$; Spanish: diff. $=3.02, p<.001, d=1.38$ ), confirming that the target tokens were code-switches, not generally accepted loanwords. 


\subsubsection{Contextualizing paragraph}

Target tokens were presented within stimuli consisting of a contrastive focus utterance, containing the target token in post-focal position, preceded by a contextualizing paragraph. The contextualizing paragraph permitted the control and manipulation of language context (i.e. experimentally-induced language mode). The contextualizing paragraphs in the monolingual contexts (examples $(1 \mathrm{a}, \mathrm{b})$ above) consisted entirely of constituents from a single language. In contrast, the bilingual contextualizing paragraphs (example (1c)) consisted of half-English and half-Spanish constituents (mean number of syllables: English $=21.96$; Spanish $=22.26 ; t(52)=-.479, p=.634)$. The use of differing amounts of each language in an experimental paradigm as a method for manipulating language mode has been supported from a theoretical perspective (Grosjean 2008), as well as in experimental work that has found that differing amounts of each language used during the experiment (e.g. stimuli) may impact both phonetic production (Olson 2013, Simonet 2014) and lexical access (Olson, published online 20 July 2015). As inducing a purely monolingual mode or context in an experimental setting may be impossible (Marian \& Spivey 2003a, b; Blumenfeld \& Marian 2007), both contexts here (monolingual and bilingual) are likely to induce a bilingual mode. However, as Grosjean (2008) notes, 'intermediate positions on the continuum' result from differing combinations of factors, including the language(s) used and amount of language switching. As such, the monolingual contexts in the current study are intended to be representative of a relatively more monolingual position on the language mode continuum than the bilingual context (see also Simonet 2014).

In the bilingual context, color signaled the language to be used by the participant, such that one language was indicated by blue, the other by red. The language-color pairing was counterbalanced across all participants. All participants received the same language-color pairing in each session. Paralleling the color conditions in the bilingual context, the monolingual contextualizing paragraphs were also presented with a color pairing of either red/purple or blue/green. If a subject received the pairing English-red, then the monolingual English context was presented in red and purple. If a subject received the pairing English-blue in the bilingual context, then the monolingual English context was presented in blue and green. This pairing system allowed consistency of language-color pairings, as well as identical usage of color alternation, in both monolingual and bilingual contexts. An equal percentage of syllables were presented in each color $(t(52)=.327, p=.745)$, and the target token, both code-switched and non-switched, was always presented in the opposite color from the immediately surrounding words. The use of color to cue language parallels previous research in psycholinguistic paradigms (e.g. Meuter \& Allport 1999, among many) and was chosen instead of other stylistic options (e.g. see Grosjean \& Miller 1994, for use of bold; Antoniou et al. 2011, for use of different scripts) as a visually-neutral way of differentiating languages.

The target token occurred in the contrastive focus utterance, a minimum of two syllables from the contrastive focus constituent (range $=2-6$ syllables; $M=2.97$ ). Given that code-switching has been associated with narrow focus from both pragmatic (e.g. Gumperz 1982, Zentella 1997) and perceptual approaches (Olson \& Ortega-Llebaria 2010), and narrow focus impacts segmental production (e.g. de Jong 2004), it was important to control for focus placement in the target utterance. As such, to ensure that focus placement was consistent across all target tokens, all targets were in a post-focal position. In addition, considering the potential influence of sentence position on VOT (Lisker \& Abramson 1967), all target tokens were a minimum of four syllables from the end of the utterance (range $=4-19$ syllables; $M=8.00$ ). Figure 1 below shows the spectrogram of a portion of a contrastive focus utterance with the target token teachers in a postfocal, deaccented position. The dashed vertical lines correspond to syllable boundaries, while the curved line represents the intonation contour. Further analysis (Olson, published online 4 February 2015) shows that speakers produced the expected, post-focal intonation contour. 


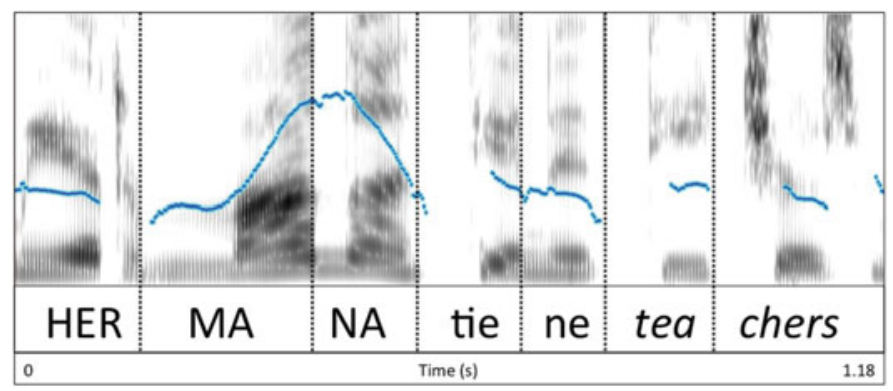

Figure 1 (Colour online) Contrastive focus utterance with the target token teachers in post-focal position, produced by an English-dominant participant.

Table 2 Session and stimuli blocks.

\begin{tabular}{ll}
\hline Session & Stimuli block \\
\hline Session A & 1. Monolingual context - non-switched, English target \\
& 2. Monolingual context - code-switched, Spanish target \\
Session B & 1. Monolingual context - non-switched, Spanish target \\
& 2. Monolingual context - code-switched, English target \\
Session C & Bilingual context - switched, English targets \\
& Bilingual context - switched, Spanish targets \\
\hline
\end{tabular}

\subsection{Procedure}

At the University of Texas at Austin, participants were seated in a quiet laboratory environment and instructed to read aloud the visually-presented stimuli (SuperLab Pro v4.1.2: Cedrus Corporation 2010) as though they were talking with 'a good friend who is also bilingual'. In the case of errors, participants were able to restart at the beginning of the utterance containing the error. To limit long-distance read-ahead effects, presentation of the utterance containing the target token occurred after the participant had read the contextualizing paragraph.

The oral production task was completed in three distinct sessions on different days in order to control for language context. Sessions were blocked as shown in Table 2. Blocking the Monolingual Context - Non-switched targets before the Monolingual Context - Codeswitched targets (i.e. Sessions A and B) allowed for clear participant expectations, and consequently a more monolingual language context. Stimuli in Session $\mathrm{C}$ were not blocked, and all bilingual stimuli were randomized together, thus speakers could potentially switch in either direction following the balanced contexts. The instructions for each session were presented visually, and the language of the instructions corresponded with the language of the session (e.g. Session A = English, Session B = Spanish, Session C = bilingual). All interaction in the lab was conducted with the same bilingual researcher in each session. Each subject received a different randomized order. The session order was counter-balanced across subjects.

Participants were recorded using a Shure Beta54 head-mounted microphone and Audacity v1.2.5 recording software with a $44.1 \mathrm{kHz}$ sampling rate. Each stimulus was repeated in three randomized sets, for a total of 477 productions per participant ( 53 stimuli $\times 3$ repetitions $\times$ 3 sessions $=477$ tokens).

\subsection{Data analysis}

A total of 6,201 tokens were initially examined and a total of 202 tokens $(3.26 \%)$ were eliminated for various errors, including laughter, yawning, and pauses in excess of $500 \mathrm{~ms}$ at the point of switch (i.e. disfluencies). The remaining tokens were coded for VOT duration using 


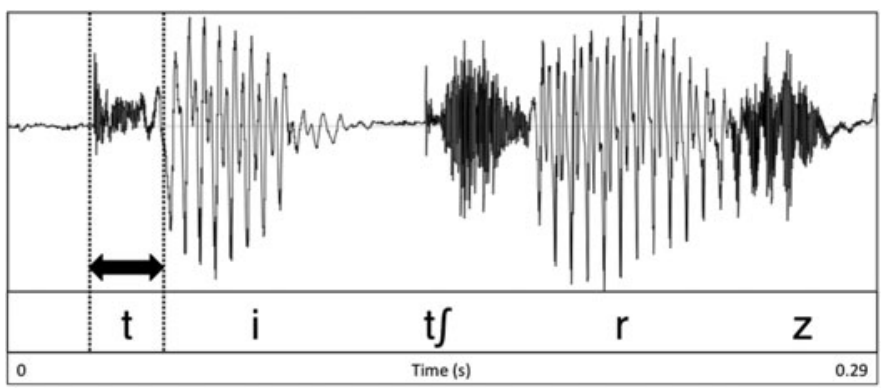

Figure 2 Target token teacher produced by an English-dominant participant. The horizontal arrow corresponds to the VOT measurement.

PRAAT 5.1.04 (Boersma \& Weenink 2009). VOT was measured as the temporal difference between the release of the oral closure and the onset of vocal fold vibration, as indicated by the presence of periodic waves and voicing bar, as seen in the spectrogram. The limits of the VOT were coded by hand, and duration measurements were extracted using an automated script. To confirm the reliability of the measurements, a subset of $10 \%$ of the total tokens $(N=620)$ were blindly recoded, revealing a high degree of intra-rater reliability $(r(618)=$ $.988, p<.001)$. Figure 2 shows the waveform for the target token teachers and the horizontal arrow corresponds to the VOT measurement.

\section{Results}

All statistical analysis was conducted using R 3.0.2 (R Core Development Team 2008), and all mixed effects models were performed with the lme4 1.1-7 package (Bates et al. 2014). For all mixed models, the alpha criterion was set at $|t|>2.0$.

Initial statistical analysis was conducted using a linear mixed effects model on VOT, with fixed factors of Condition (Monolingual Context - Non-switched; Monolingual Context Code-switched; and Bilingual Context - Code-switched), Language Dominance (Englishdominant; Spanish-dominant) and Response Language (English; Spanish). Subject and Item were included as random factors with both random slopes and intercepts for each of the main factors and their interactions (see Barr et al. 2013). To test the potential impact of these factors, three subsequent mixed effects models were conducted, identical to the original, but eliminating one of the fixed effects in each model. The original model with all three fixed effects (LogLik = 16622) was then compared to each of the three subsequent models. Results indicated that exclusion of each of the fixed effects significantly degraded the model fit: Condition $\left(\operatorname{LogLik}=16610, \chi^{2}(8)=25.619, p=.001\right)$, Language Dominance $\left(\operatorname{LogLik}=16613, \chi^{2}(6)=19.631, p=.003\right)$, and Response Language (LogLik $=16606$, $\left.\chi^{2}(6)=16.71, p<.001\right)$. In sum, the inclusion of each of the fixed effects is warranted by the model comparison.

Considering the original model, including all three fixed effects, the results revealed that there was a significant effect of both Condition and Response Language on VOT. There was a significant difference between the Intercept (Monolingual Context - Non-switched; Englishdominant, English) and each of the two code-switched conditions (Monolingual Context Code-switched: $\beta=-16.4, t=-2.069$; Bilingual Context - Code-switched: $\beta=-19.0, t=$ $-2.809)$. In addition, there were also significant differences between the intercept (English) and the Spanish condition $(\beta=-46.1, t=-7.449)$. Also worth noting, there were significant two-way interactions for Condition $\times$ Language Dominance $(\beta=14.4, t=2.021)$ and 
Table 3 Fixed effects of linear mixed effects model (CS = code-switches).

\begin{tabular}{lrrrrr}
\hline & Estimate & Std. Error & t-value & Left Cl & Right Cl \\
\hline Intercept & 72.9 & 5.34 & 13.56 & 62.22 & 83.50 \\
Monolingual context CS & -16.4 & 7.94 & -2.06 & -32.28 & -0.52 \\
Bilingual context CS & -19.0 & 6.77 & -2.81 & -32.54 & -5.46 \\
Spanish-dominant & -14.8 & 8.20 & -1.77 & -31.20 & 1.60 \\
Spanish & -46.1 & 6.18 & -7.45 & -58.46 & -33.74 \\
Monolingual context CS: Spanish-dominant & 7.2 & 8.55 & 0.85 & -9.90 & 24.30 \\
Bilingual context CS: Spanish-dominant & 14.3 & 7.11 & 2.02 & 0.08 & 28.52 \\
Monolingual context CS: Spanish & 17.1 & 9.25 & 1.05 & -1.40 & 35.60 \\
Bilingual context CS: Spanish & 22.2 & 8.60 & 2.50 & 5.00 & 39.40 \\
Spanish-dominant: Spanish & 11.9 & 8.59 & 1.39 & -5.28 & 29.08 \\
Monolingual context CS: Spanish-dominant: Spanish & -2.8 & 10.12 & -0.28 & -23.04 & 17.44 \\
Bilingual context CS: Spanish-dominant: Spanish & -13.2 & 8.91 & -1.49 & -31.02 & 4.62 \\
\hline
\end{tabular}

Condition $\times$ Response Language $(\beta=22.2, t=2.584)$. Results for all fixed effects are found in Table 3. To better understand the impacts of each of the fixed effects, secondary mixed models were conducted for each language dominance group in both English and Spanish.

\subsection{Results for English tokens}

A secondary mixed effects model was conducted for the English VOTs produced by the English-dominant group with Condition as a main effect and Subject and Item as random effects with random intercepts and slopes by Condition. An analysis of the results revealed a significant impact of Condition on VOT. Both the Monolingual Context Code-switched $(M=56.5 \mathrm{~ms}, S D=25.7 \mathrm{~ms} ; \beta=-16.2, t=2.083)$ and the Bilingual Context - Code-switched $(M=53.9 \mathrm{~ms}, S D=23.9 \mathrm{~ms} ; \beta=-18.9, t=2.786)$ conditions were produced with significantly shorter VOTs than the Monolingual Context - Non-switched condition $(M=72.9 \mathrm{~ms}, S D=20.1 \mathrm{~ms})$. Also worth noting, there was no significant difference in the VOT produced in the two code-switched conditions $(\beta=-2.6, t=-1.456)$. As such, while all English code-switched tokens were produced with shorter, more Spanish-like VOTs, there was no difference between the code-switches produced in the monolingual and bilingual contexts.

An identical model conducted on English tokens produced by the Spanish-dominant speakers revealed a similar pattern. Again, the Monolingual Context - Code-switched $(M=$ $49.9 \mathrm{~ms}, S D=25.2 \mathrm{~ms} ; \beta=-9.2, t=2.693)$ and Bilingual Context - Code-switched $(M=$ $53.1 \mathrm{~ms}, S D=25.4 \mathrm{~ms} ; \beta=-4.7, t=-2.007)$ tokens were produced with significantly shorter VOTs than their Monolingual Context - Non-switched counterparts $(M=57.9 \mathrm{~ms}, S D=$ $26.9 \mathrm{~ms}$ ). Unlike the English-dominant group, there was a significant difference between the Monolingual Context - Code-switched and Bilingual Context - Code-switched tokens $(\beta=$ $-4.6, t=-2.050)$. Though one may hypothesize additional transfer in the bilingual context relative to the monolingual context, the difference presented here is actually in the opposite direction. That is, the code-switched tokens in the bilingual context were actually produced with LONGER VOTs than the code-switched tokens in the monolingual context.

In sum, as can be seen in Figure 3, both groups of bilinguals showed an effect of code-switching on their production of voice onset time. VOTs produced for English codeswitched tokens were significantly shorter, or more Spanish-like, than the non-switched tokens. Furthermore, while the English-dominant subjects showed no difference between VOTs produced for code-switched tokens in the monolingual and bilingual contexts, the 


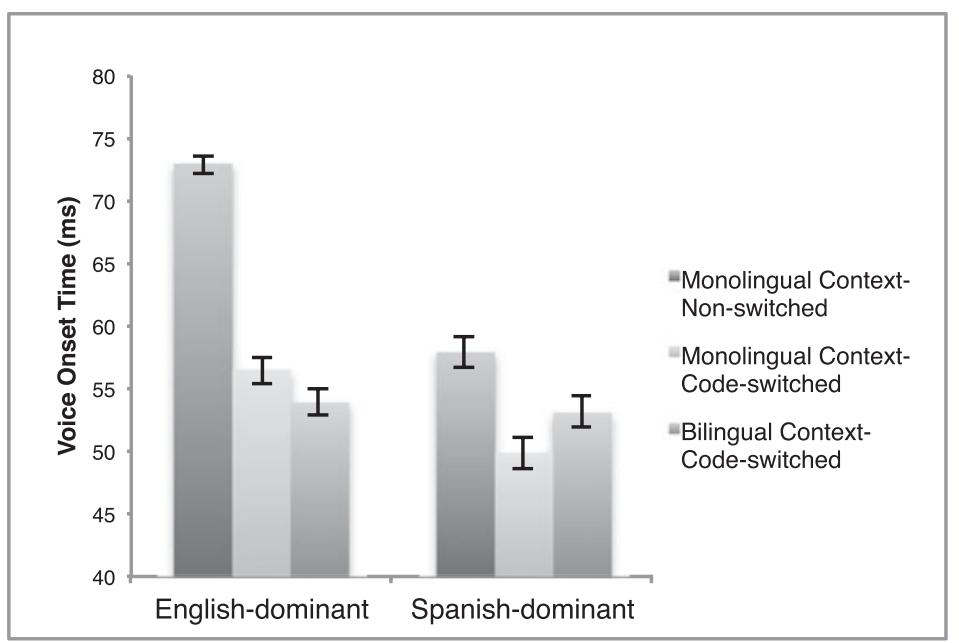

Figure 3 VOT for English tokens presented by language dominance group. Error bars represent +/-1 SE.
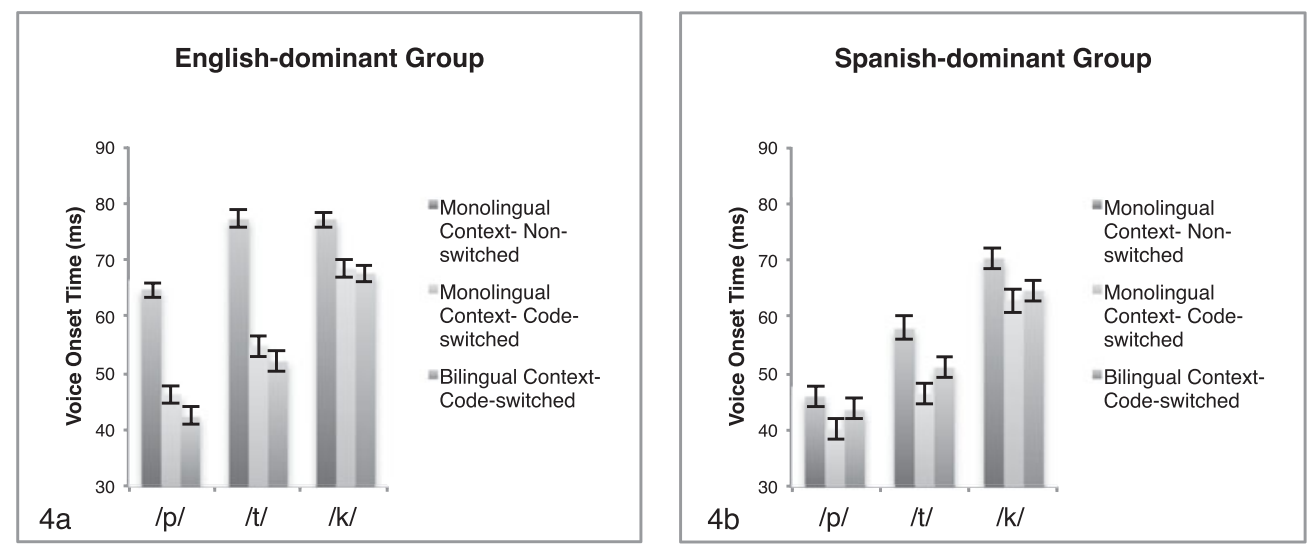

Figure 4 VOT for English tokens presented by initial phoneme for the English-dominant group (4a) and the Spanish-domainant group (4b). Error bars represent +/-1 SE.

Spanish group showed significantly longer (i.e. less transfer) for code-switched tokens in the bilingual context to relative to the monolingual context.

Lastly, while the impact on each different place of articulation is not the main focus of the current study, it is worth noting that this pattern appears to be consistent across all places of articulation, as seen in Figure 4.

\subsection{Results for Spanish tokens}

Parallel analysis conducted on Spanish tokens revealed a distinct pattern. For Spanish tokens produced by the English-dominant group, an identical mixed model analysis revealed no significant impact of Condition on VOT, such that the VOT produced in the Monolingual Context - Code-switched $(M=27.7 \mathrm{~ms}, S D=15.3 \mathrm{~ms})$ and Bilingual Context - Codeswitched $(M=30.3 \mathrm{~ms}, S D=18.2 \mathrm{~ms})$ conditions did not differ from the Monolingual Context - Non-switched condition $(M=27.2 \mathrm{~ms}, S D=13.6 \mathrm{~ms})(|t|<1.000)$. There was 


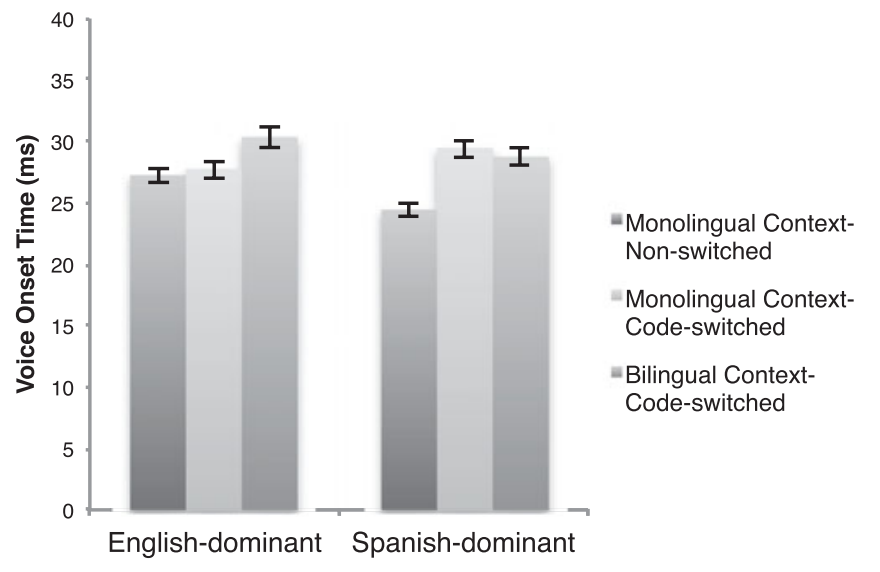

Figure 5 VOT for Spanish tokens presented by language dominance group. Error bars represent +/-1 SE. For purposes of comparison, the range of vertical scale parallels that used for English tokens (see Figure 3 above).
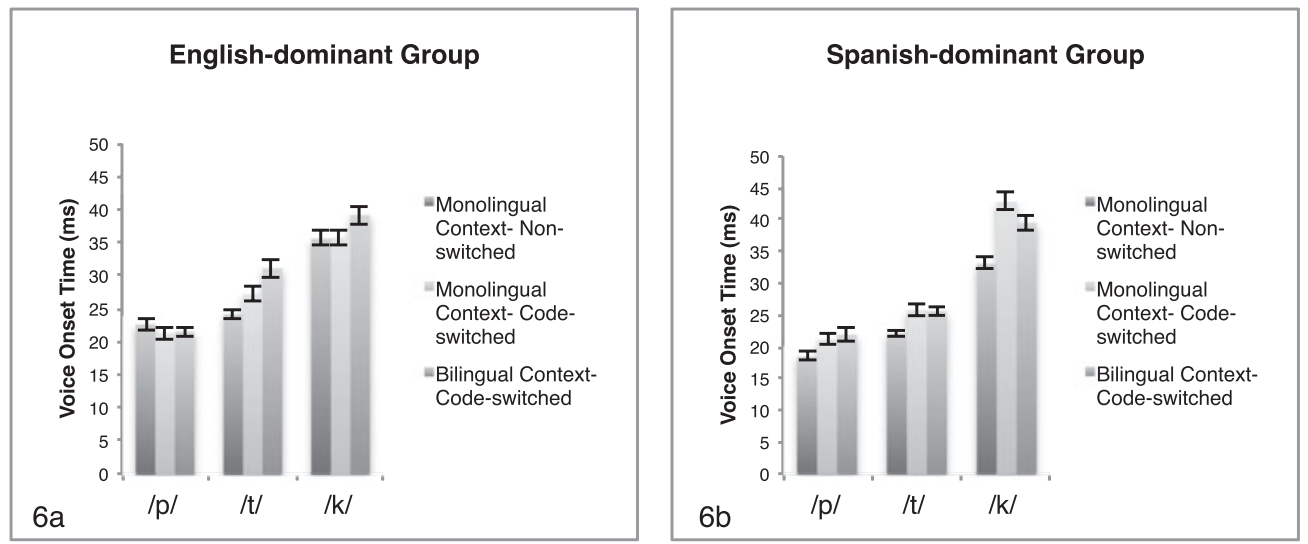

Figure 6 VOT for Spanish tokens presented by initial phoneme for the English-dominant group (6a) and the Spanish-dominant group (6b). Error bars represent $+/-1 \mathrm{SE}$.

also no difference between the tokens produced in the Monolingual Context - Code-switched and Bilingual Context - Code-switched tokens $(\beta=-2.5, t=1.056)$.

In contrast, the model conducted for Spanish tokens produced by the Spanish-dominant group does indicate a significant impact of Condition on VOT. Both the Monolingual Context - Code-switched $(M=29.4 \mathrm{~ms}, S D=15.9 \mathrm{~ms} ; \beta=4.8, t=3.604)$ and the Bilingual Context - Code-switched tokens $(M=28.7 \mathrm{~ms}, S D=14.6 \mathrm{~ms} ; \beta=4.1, t=4.352)$ were produced with longer, more English-like VOTs than the Monolingual Context - Non-switched tokens $(M=24.4, S D=10.8 \mathrm{~ms})$. Again, there was no significant difference between the VOTs produced in two sets of code-switched tokens $(\beta=-0.7, t=-0.591)$.

As illustrated in Figure 5, the English-dominant and Spanish-dominant groups showed somewhat different effects of code-switching on their production of Spanish VOTs. Specifically, while English-dominant speakers showed no effect of code-switching, Spanish 
VOTs for code-switched tokens produced by the Spanish-dominant group were significantly longer, or more English-like, than the non-switched tokens. Considering the effect of language context, neither group showed any difference in the VOTs produced in the two code-switched contexts. Again this pattern appears to be consistent across all places of articulation, as seen in Figure 6.

It is relevant to also note the difference in magnitudes for the code-switching effects on English and Spanish tokens. English tokens (Figure 3 above), when comparing the Monolingual Context - Non-switched and Monolingual Context - Code-switched tokens, showed a greater shift in VOT (English-dominant speakers: $17 \mathrm{~ms}$; Spanish-dominant speakers: $8 \mathrm{~ms}$ ) than Spanish tokens (Figure 5) (English-dominant speakers: $0.5 \mathrm{~ms}$; Spanishdominant speakers: $5 \mathrm{~ms}$ ).

\section{Discussion}

Taken as a whole, two general trends emerge from the results relating directly to the research questions (Section 2.3, above). With respect to the first research question, whether codeswitching impacts segmental production, the hypothesis is confirmed. When comparing the non-switched tokens to the code-switched tokens, and particularly code-switched tokens in a monolingual context, the results demonstrate phonetic transfer. Worth noting, the phonetic interactions found were not identical in the two groups, with English-dominant speakers evidencing unidirectional transfer and Spanish-dominant speakers evidencing bidirectional transfer. With respect to the second research question, whether is there a cumulative impact of code-switching and language mode on phonetic production, the hypothesis is not substantiated. While the previous literature clearly demonstrates an impact of code-switching and language mode individually, these two sources of phonetic interaction do not seem to create a cumulative effect. Each of these findings is discussed further below.

\subsection{Effect of code-switching on phonetic production}

The results of the current study, namely that code-switching impacts phonetic production, add to the growing body of research supporting a degree of phonetic transfer associated with a change in languages (Bullock et al. 2006, Bullock \& Toribio 2009, Antoniou et al. 2011, Balukas \& Koops 2015, Piccinini \& Arvaniti 2015), as opposed to a 'complete' phonetic switch (Grosjean \& Miller 1994). However, the type of transfer found in the current results differed depending on the language background of the two speaker groups. English-dominant speakers demonstrated unidirectional transfer, with significantly shorter English VOTs for code-switched tokens relative to non-switched tokens, but no difference in Spanish VOTs between the various contexts. In contrast, Spanish-dominant speakers produced evidence of bi-directional transfer, with code-switched English tokens produced with shorter VOTs than non-switched tokens and code-switched Spanish tokens produced with longer VOTs than non-switched tokens.

The finding of unidirectional transfer in the current study, specifically short to long lag transfer (i.e. Spanish to English), parallels the most common finding in the previous literature. This short to long lag transfer has been previously found for speakers dominant in long lag languages (Antoniou et al. 2011, Bullock et al. 2006) and dominant in short lag languages (Bullock et al. 2006), and has been found in both laboratory speech and natural speech contexts (Balukas \& Koops 2015). These results, both from the current study and previous literature, seem to find explanation in the previous suggestion (Bullock et al. 2006) that long lag languages, with significantly greater acceptable VOT ranges (e.g. approximately $70 \mathrm{~ms}$ for long lag languages vs. $30 \mathrm{~ms}$ for short lag languages), allow more 'room' for 
phonetic transfer (see also Piccinini \& Arvaniti 2015). Given the wider range of Englishlike VOTs, speakers have some flexibility to produce significantly shorter VOTs, without producing tokens that are decidedly non-English-like. It is worth mentioning that what is deemed 'decidedly non-English-like' by a given speaker may depend on a variety of factors. As a number of researchers have pointed out, while bilinguals maintain two different sets of phonetic norms, these norms may be distinct from those in the monolingual community (e.g. Caramazza et al. 1972, Flege \& Port 1981, Flege \& Hillenbrand 1984, Flege \& Eefting 1987, Major 1987). As such, it is possible to posit that the range of what is considered 'English-like' may be determined by the norm of the larger monolingual community, by the non-switched norms of the bilingual community, or even some fluid implementation of both (e.g. for shifts in non-switched phonetic productions based on a speaker's perception of a listener's language background, see Khattab 2009).

As previous studies have mostly documented unidirectional transfer, with the exception of early bilinguals (Bullock \& Toribio 2009), the current study provides some evidence for the possibility of bi-directional transfer in highly proficient late bilinguals, as seen in the English to Spanish transfer in the Spanish-dominant group. That is, the English-dominant group produced the more expected unidirectional transfer, and the Spanish-dominant group evidenced bi-directional transfer. A parallel can be found in Bullock \& Toribio (2009), who noted that participants demonstrating bi-directional transfer were those who produced the shortest Spanish VOTs in non-switched contexts, which effectively may have allowed for the 'phonetic latitude' to license convergence (p. 202). ${ }^{2}$ Similarly, as noted in the results (Section 4), the magnitude of the shift in VOT in the two languages is also relevant. In English, code-switches (in the monolingual context) shifted VOT production by approximately 12.5 $\mathrm{ms}$, while in Spanish, the shift was only $2.5 \mathrm{~ms}$. That is, English allows sufficient range for greater transfer, which was significant for both groups. Spanish, with a more compressed VOT range, permits less transfer, and was significant only for the Spanish-dominant speakers. $^{3}$

This interpretation also finds support from the effect of cognate status on VOT production (Amengual 2012), another case in which dual activation of the two languages may be possible. In the examination of VOT in Spanish tokens produced by four different dominance groups of Spanish-English bilinguals, Amengual (2012) found that there was an effect of cognate status on VOT, such that Spanish words with English cross-linguistic cognates were produced with significantly greater VOT than words without cognates. Importantly, the overall magnitude of these effects was small (1.2-4.3 ms), and averages for /t/ were never superior to $21 \mathrm{~ms}$ for any of the four groups. Furthermore, the group with the highest overall Spanish VOT average for non-cognate items, Heritage English speakers, was the LEAST LIKELY to show cognate effects. This pattern largely holds for the individuals in the other language background groups as well. Subjects with shorter non-cognate VOT averages were more likely to evidence cognate effects and phonetic transfer. Thus, much like findings in the current study, as well as Bullock $\&$ Toribio (2009), groups or subjects with shorter Spanish VOTs are more likely to evidence

\footnotetext{
${ }^{2}$ A similar (non-significant) trend emerged in the current study, with Spanish-dominant speakers producing shorter VOTs in Spanish in the non-switched condition than the English-dominant speakers.

${ }^{3} \mathrm{~A}$ second parallel can be noted with recent findings in a cued language-switching paradigm, in which Spanish-dominant bilinguals (Spanish-English) evidenced unidirectional transfer, with the dominant language impacted by phonetic transfer (Olson 2013). It was tentatively suggested that this asymmetry may be indicative of inhibitory mechanisms of language selection, in which the L1 receives greater inhibition than the L2 (for the lexical level, see Green (1986, 1998), among many). Within this interpretation, while long lag languages are inherently susceptible to phonetic transfer, short lag languages with a reduced range, may be sensitive indicators of underlying inhibitory processes. However, Olson (2013) notes that it is not clear how an inhibitory approach may work in connected speech, relative to a cued switching paradigm. Furthermore, it is not clear how this approach would account for previous failures to find similar asymmetries for short-lag dominant subjects (e.g. Bullock \& Toribio 2009).
} 
transfer effects. In short, subjects with more 'room' are more likely to demonstrate the expected transfer effects.

Additional grounding for this analysis comes not only from situations of dual activation, such as code-switching and cognates, but similar impacts of VOT range can be seen in monolingual speakers in the effects of speech rate (Magloire \& Green 1999). Namely, monolingual English speakers (and Spanish-English bilinguals) have been shown to exhibit a strong negative correlation between speech rate and English VOT, such that slower speech rate corresponds to an increase in voice onset time duration (e.g. Kessinger \& Blumstein 1997). In contrast, monolingual Spanish speakers and Spanish-English bilinguals demonstrated a much weaker correlation between speech rate and Spanish VOT. Decreases in speech rate had a minimal impact on VOT in Spanish (Magloire \& Green 1999; for French see Kessinger \& Blumstein 1997). Again, English, with a greater acceptable VOT range, permits greater VOT variation, whereas Spanish, with a more limited VOT range, shows much less variability.

What is clear is that although long lag languages appear to be more susceptible to phonetic transfer, short lag languages are not necessarily immune, even in late bilingual populations.

\subsection{The role of language context and limits on phonetic transfer}

One notable finding in the current work was the lack of a cumulative effect of code-switching and bilingual language context on phonetic production. As stated in the hypotheses, given that both code-switching and bilingual language mode have been shown to serve as catalysts for phonetic interaction and represent situations in which both languages must be accessed within a compressed timeframe, if not simultaneously, it was anticipated that code-switching in a bilingual context would drive greater levels of phonetic transfer than code-switching in a monolingual context. However, this was not the case. While there were largely no differences between the code-switched tokens in the monolingual and bilingual contexts, the only significant difference between code-switched tokens in the two contexts actually occurred in the opposite direction (i.e. English tokens produced by the Spanish-dominant group), with the bilingual code-switched tokens produced with LESS phonetic transfer than those produced in the monolingual context. ${ }^{4}$ This general lack of a cumulative effect may provide some insight into the nature of the phonetic transfer in situations of active bilingualism. Specifically, it is possible that the results presented here suggest limits on the amount of phonetic transfer permissible or possible in bilingual speech. Speakers may produce tokens with a degree of transfer, but still strive to produce tokens that are intelligible, comprehensible, and decidedly English- or Spanish-like.

This argument ties directly into the above discussion on the inherent VOT ranges for long and short lag languages. Given that code-switching represents a case in which two languages are accessed in a compressed time frame, it is possible that such dual activation serves as a point of maximal interlanguage interaction and maximal phonetic interaction. In terms of phonetic production in the current study, code-switching may serve to push VOT production to the boundary of what is considered to be English or Spanish-like. Thus, code-switching in a bilingual context, which may in principle be assumed to generate greater activation of both languages, may fail to produce any additional evidence of phonetic transfer as code-switching alone causes tokens to be produced at the lower end of the acceptable boundary. In short, while code-switching and bilingual language context may independently result in phonetic

\footnotetext{
${ }^{4}$ As noted by a reviewer, it may be that bilingual context actually increases activation of the target language, as there is target language material present in the context prior to the target token. While bilingual mode might push for more transfer for non-switched tokens (e.g. Simonet 2014), it may have the opposite effect for switched tokens. This issue certainly warrants additional study.
} 
transfer, there is not sufficient 'room' for an additive effect without tokens being considered decidedly non-normative.

It is worth noting that this explanation relies inherently on the assumption that the two contexts used in the current study represent or induce different positions on the language mode continuum. While this assumption is supported both by theoretical accounts of language mode (Grosjean 2008) and in line with previous experimental findings in phonetics (Simonet 2014, Olson, published online 4 February 2015) and psycholinguistics (Olson, published online 20 July 2015), such findings and the resulting explanation should be taken as tentative, and certainly invite future research. In sum, although previous studies have shown that that code-switches differ depending on the language context, such differences at the segmental level (i.e. VOT) may be masked or constrained by each language's inherent norms.

\section{Conclusion}

The present study examined the impact of code-switching and language context on voice onset time (VOT) production in two groups of Spanish-English bilinguals (i.e. English-dominant and Spanish-dominant). Both code-switching and bilingual language context have been shown to serve as potential catalysts for interlanguage interaction (e.g. Bullock et al. 2006, Simonet 2014), given that they represent situations in which both of a bilingual's languages must be accessed in a compressed timeframe.

With respect to the impact of code-switching on phonetic production, results illustrated both unidirectional transfer, with long lag English VOTs being produced with significantly shorter, more Spanish-like durations (English-dominant group), and bi-directional transfer, with productions in both languages mutually impacted by code-switching (Spanish-dominant group). While unidirectional transfer has been the most common finding reported in the literature, the current results demonstrate that bi-directional transfer is possible, even in late bilingual populations. These results, in conjunction with previous results for the impact of code-switching on VOT (e.g. Bullock \& Toribio 2009), the effect of cognate status on VOT (e.g. Amengual 2012), and even VOT variability driven by speech rate (e.g. Magloire \& Green 1999), suggest potential inherent limits on phonetic transfer in situations of dual language activation.

With respect to the cumulative impact of code-switching and bilingual language context on VOT production, contrary to the original hypothesis, there was no significant difference found between the VOTs of code-switched tokens produced in a monolingual context and those produced in a bilingual context. Again, these results suggest limits on phonetic transfer, whereby code-switching alone induces VOT values at the boundary of the acceptable range, and as such code-switching in a more bilingual context does not beget any 'additional' transfer. These results should not be taken as evidence that code-switches in monolingual and bilingual contexts are necessarily indistinguishable, particularly in light of previous research (e.g. Simonet 2014, Olson, published online 4 February 2015), but rather that with respect to VOT, inherent limits on phonetic transfer may mask underlying differences in the two realizations.

Although the current study tacitly suggests limits on the extent of phonetic transfer, there are a number of areas for future research that will serve to challenge or confirm this tentative proposal. In addition to addressing other phonetic features beyond VOT, which has been the base for much of the previous research, future work should draw from different experimental and naturalistic paradigms to expand on the current and previous findings. This work should address bilingual populations of different language backgrounds, including different dominance and age of acquisition profiles. Furthermore, it is readily acknowledged that the mechanisms responsible for such limits on phonetic 
transfer have yet to be fully examined. It may be the case that such limits are driven by communicative constraints and interlocutor expectations, with malleable limits set on the basis of given conversational variables, or rather by some inherent phonetic or cognitive limitations, with more strictly fixed boundaries. Future work may continue to explore the limitations on phonetic transfer and address the underlying nature of such transfer constraints.

\section{Acknowledgements}

This work was supported in part by the National Science Foundation under Grant 1024320. Any opinions, findings, and conclusions or recommendation expressed in this material are those of the author and do not necessarily reflect the views of the National Science Foundation. I would also like to thank A .J. Toribio, B. Bullock, and the anonymous reviewers for their time and efforts. Any errors are my own.

\section{Appendix A. Additional participant background information}

Table A1 Additional participant background information (AoA $=$ age of acquisition).

\begin{tabular}{llcllll}
\hline Group & Participant & Age & $\begin{array}{l}\text { English } \\
\text { AoA }\end{array}$ & $\begin{array}{l}\text { Spanish } \\
\text { AoA }\end{array}$ & $\begin{array}{l}\text { Place of } \\
\text { birth }\end{array}$ & $\begin{array}{l}\text { Residence in opposite } \\
\text { language community }\end{array}$ \\
\hline English-dominant & E1 & 27 & 0 & 19 & USA & Mexico \\
English-dominant & E2 & 24 & 0 & 14 & USA & Chile \\
English-dominant & E3 & 35 & 0 & 25 & USA & Mexico \\
English-dominant & E4 & 28 & 0 & 13 & USA & USA (South Texas) \\
English-dominant & E5 & 25 & 0 & 12 & USA & Spain \\
English-dominant & E6 & 26 & 0 & 12 & USA & Mexico \\
English-dominant & E7 & 27 & 0 & 12 & USA & USA (South Texas) \\
Spanish-dominant & S1 & 19 & 12 & 0 & Mexico & USA \\
Spanish-dominant & S2 & 19 & 12 & 0 & Mexico & USA \\
Spanish-dominant & S3 & 26 & 12 & 0 & Bolivia & USA \\
Spanish-dominant & S4 & 31 & 12 & 0 & Ecuador & USA \\
Spanish-dominant & S5 & 18 & 15 & 0 & Mexico & USA \\
Spanish-dominant & S6 & 18 & 14 & 0 & Mexico & USA \\
\hline
\end{tabular}

${ }^{a}$ The dominant language of a particular community of residence was determined by the participant.

\section{Appendix B. Translation of English Target Stimuli: Example 1}

a. Monolingual Context-Non-switched

I went to my daughter's school, because I had a meeting about her behavior, but I went to the wrong classroom.

The nice lady smiled, and said "No, not me. MS. HARRISON AND MRS. SMITH are the teachers in charge of your daughter's class."

b. Monolingual Context - Code-switched

Salió un reportaje sobre la gente que trabaja en las escuelas públicas.

Mi madre me preguntó, “¿Tu escuela tiene buena gente?"

“¿Mi escuela? No, pero la escuela de mi HERMANA tiene teachers muy buenos que enseñan a los niños."

'A report came out about the people that work in public schools

My mother asked me, "Does your school have good people?" 
"My school? No, but my SISTER'S school has very good teachers that work with the children."”

c. Bilingual Context-Code-switched

My parents wanted the escuela with the best people to educate me.

"La escuela pública tiene los mejores?" my mom asked.

"No, la PRIVADA tiene teachers muy buenos en cada clase," my dad told her.

'My parents wanted the school with the best people to educate me.

"The public school has the best people?" my mom asked.

"No, the PRIVATE school has really good teachers in every classroom," my dad told her.'

\section{Appendix C. Sample Spanish target stimuli}

a. Monolingual Context - Non-switched Mis padres viven en un barrio con mucha violencia.

“¿Tu padre ha visto o escuchado gente con pistolas?” preguntó mi amigo.

"No, pero MI MADRE ha escuchado tiros casi todas las noches de los pandilleros con armas."

'My parents live in a neighborhood with a lot of violence.

"Has your father seen or heard people with pistols?" my friend asked.

"No, but MY MOTHER has heard gunshots almost every night from the gang members with guns."

b. Monolingual Context-Code-switched

There was a drive-by shooting in my neighborhood, and the police were interviewing people.

"Did you run when you heard it?" the officer asked me.

"No, I DUCKED when I heard the tiros coming from the car."

'There was a drive-by shooting in my neighborhood, and the police were interviewing people.

"Did you run when you heard it?" the officer asked me.

"No, I DUCKED when I heard the gunshots coming from the car."

c. Bilingual Context-Code-switched

Mi tío tiene muchas armas. Pistols and shotguns are his favorites.

"Do you think that the shotgun hace más ruido?"

"No, I don't think ... I KNOW that the tiros of the shotgun make the most noise."

'My uncle has a lot of weapons. Pistols and shotguns are his favorites.

"Do you think that the shotgun makes the most noise?"

"No, I don't think... I KNOW that the gunshots of the shotgun make the most noise."”

\section{References}

Amengual, Mark. 2012. Interlingual influence in bilingual speech: Cognate status effect in a continuum of bilingualism. Bilingualism: Language and Cognition 15(3), 517-530.

Antoniou, Mark, Catherine T. Best, Michael D. Tyler \& Christian Kroos. 2011. Inter-language interference in VOT production by L2-dominant bilinguals: Asymmetries in phonetic code switching. Journal of Phonetics 39(4), 558-570.

Balukas, Colleen \& Christian Koops. 2015. Spanish-English bilingual voice onset time in spontaneous code-switching. International Journal of Bilingualism 19(4), 423-443.

Barr, Dale, Roger Levy, Christoph Scheepers \& Harry Tily. 2013. Random effects structure for confirmatory hypothesis testing: Keep it maximal. Journal of Memory and Language 68, 255-278. 
Bates, Douglas, Martin Maechler, Ben Bolker \& Steven Walker S. 2014. lme4: Linear mixed-effects models using Eigen and S4 (R package version 1.1-7). http://CRAN.R-project.org/package=lme4 (accessed 1 February 2014).

Best, Catherine T. \& Michael Tyler. 2007. Nonnative and second-language speech perception: Commonalities and complementarities. In Ocke-Schwen Bohn \& Murray J. Munro (eds.), Second language speech learning: The role of language experience in speech perception and production, 13-34. Amsterdam: John Benjamins.

Blumenfeld, Henrike \& Viorica Marian. 2007. Constraints on parallel activation in bilingual spoken language processing: Examining proficiency and lexical status using eye-tracking. Language and Cognitive Processes 22(5), 633-660.

Boersma, Paul \& David Weenink. 2009. Praat: Doing phonetics by computer (version 5.1.07). http://www.praat.org (accessed 10 January 2009).

Bosch, Laura \& Nuria Sebastian-Galles. 2003. Simultaneous bilingualism and the perception of a languagespecific vowel contrast in the first year of life. Language and Speech 46, 217-243.

Bullock, Barbara E. \& Almeida J. Toribio. 2009. Trying to hit a moving target: On the sociophonetics of code-switching. In Ludmila Isurin, Donald Winford \& Kees de Bot (eds.), Multidisciplinary approaches to code-switching, 189-206. Philadelphia, PA: John Benjamins.

Bullock, Barbara E., Almeida J. Toribio, Veronica González López \& Amanda Dalola. 2006. Language dominance and performance outcomes in bilingual pronunciation. In Mary Grantham O'Brien, Christine Shea \& John Archibald (eds.), Proceedings of the 8th Generative Approaches to Second Language Acquisition Conference, 9-16. Somerville, MA: Cascadilla Proceedings Project.

Caramazza, Alfonso, Grace H. Yeni-Komshian, Edgar B. Zurif \& Evelyn Carbone. 1973. The acquisition of a new phonological contrast: The case of stop consonants in French-English bilinguals. Journal of the Acoustical Society of America 54(2), 421-428.

Cedrus Corporation. 2010. SuperLab Pro (version 4.1.2). San Pedro, CA.

Chan, Brian. 2003. Aspects of the syntax, the pragmatics and the production of code switching: Cantonese and English (Berkeley Insights in Linguistics and Semiotics 51). New York: Peter Lang.

Chincotta, Dino \& Geoffrey Underwood. 1998. Non-temporal determinants of bilingual memory capacity: The role of long-term representations and fluency. Bilingualism: Language and Cognition 1, 117-130.

de Groot, Annette M. B. 1992. Bilingual lexical representation: A closer look at conceptual representations. In Ram Frost \& Leonard Katz (eds.), Orthography, phonology, morphology, and meaning, 389-412. Amsterdam: Elsevier.

de Jong, Kenneth. 2004. Stress, lexical focus, and segmental focus in English: Patterns of variation in vowel duration. Journal of Phonetics 32, 493-516.

Fabiano-Smith, Leah \& Jessica A. Barlow. 2010. Interaction in bilingual phonological acquisition: Evidence from phonetic inventories. International Journal of Bilingual Education and Bilingualism $13(1), 1-19$.

Flege, James Emil. 1995. Second language speech learning: Theory, findings, and problems. In Winifred Strange (ed.), Speech perception and linguistic experience in cross-language research, 233277. Timonium, MD: York Press.

Flege, James Emil \& Wieke Eefting. 1987. Production and perception of English stops by native Spanish speakers. Journal of Phonetics 15, 67-83.

Flege, James Emil \& James Hillenbrand. 1984. Limits on phonetic accuracy in foreign language speech production. Journal of the Acoustical Society of America 76(3), 708-721.

Flege, James Emil, Ian R. A. Mackay \& Thorsten Piske. 2002. Assessing bilingual dominance. Applied Psycholinguistics 23, 567-598.

Flege, James Emil \& Robert Port. 1981. Cross-language phonetic interference: Arabic to English. Language and Speech 24, 125-146.

Flege, James Emil, Grace H. Yeni-Komshian \& Serena Liu. 1999. Age constraints on second language acquisition. Journal of Memory and Language 41, 78-104.

Fowler, Carol A., Valery Sramko, David J. Ostry, Sarah A. Rowland \& Pierre Hallé. 2008. Cross language phonetic influences on the speech of French-English bilinguals. Journal of Phonetics 36, 649-663. 
González López, Verónica. 2012. Spanish and English word-initial voiceless stop production in codeswitched vs. monolingual structures. Second Language Research 28(2), 243-263.

Green, David W. 1986. Control, activation and resource: A framework and a model for the control of speech in bilinguals. Brain and Language 27, 210-223.

Green, David W. 1998. Mental control of the bilingual lexico-semantic system. Language and Cognition $1,67-81$.

Grosjean, François. 1982. Life with two languages: An introduction to bilingualism. Cambridge, MA: Harvard University Press.

Grosjean, François. 1997. Processing mixed language: Issues, findings, and models. In Annette M. B. de Groot \& Judith F. Kroll (eds.), Tutorials in bilingualism: Psycholinguistic perspectives, 225-254. Mahwah, NJ: Lawrence Erlbaum.

Grosjean, François. 1998. Transfer and language mode. Bilingualism: Language and Cognition 1(3), 175-176.

Grosjean, François. 2001. The bilingual's language modes. In Janet Nicol (ed.), One mind, two languages: Bilingual language processing, 1-21. Malden, MA: Blackwell.

Grosjean, François. 2008. Studying bilinguals. Oxford: Oxford University Press.

Grosjean, François \& Joanne L. Miller. 1994. Going in and out of languages: An example of bilingual flexibility. Psychological Science 5, 201-206.

Gumperz, John J. 1982. Discourse strategies. Cambridge: Cambridge University Press.

Hazan, Valerie L. \& Georges Boulakia. 1993. Perception and production of a voicing contrast by FrenchEnglish bilinguals. Language and Speech 36, 17-38.

Jia, Gisela, Dorris Aaronson \& Yanhong Wu. 2002. Long-term attainment of bilingual immigrants: Predictive variables and language group differences. Applied Psycholinguistics 23, 599-621.

Ju, Min \& Paul Luce. 2004. Falling on sensitive ears. Pscyhological Science 15, 314-318.

Kehoe, Margaret, Conxita Lleó \& Martin Rakow. 2004. Voice onset time in bilingual German-Spanish children. Bilingualism: Language and Cognition 7(1), 71-88.

Keshavarz, Mohhamad Hossein \& David Ingram. 2002. The early phonological development of a FarsiEnglish bilingual child. International Journal of Bilingualism 6(3), 255-269.

Kessinger, Rachel H. \& Sheila E. Blumstein. 1997. Effects of speaking rate on voice-onset time and vowel production: Some implications for perception studies. Journal of Phonetics 26(2), 117-128.

Khattab, Ghada. 2009. Phonetic accommodation in children's code switching. In Barbara Bullock \& Almeida Jacqueline Toribio (eds.), The Cambridge handbook of linguistic code switching, 142-160. Cambridge: Cambridge University Press.

Kroll, Judith \& Erika Stewart. 1994. Category interference in translation and picture naming: Evidence for asymmetric connections between bilingual memory representations. Journal of Memory and Language 33, 149-174.

Ladefoged, Peter. 2003. Phonetic data analysis. Malden, MA: Blackwell.

Lisker, Leigh \& Arthur Abramson. 1964. A cross-language study of voicing in initial stops. Word 20, 284-422.

Lisker, Leigh \& Arthur Abramson. 1967. Some effects of context on voice onset time in English stops. Language and Speech 10, 1-28.

Mack, Molly. 1989. Consonant and vowel perception and production: Early English-French bilinguals and English monolinguals. Attention, Perception, \& Psychophysics 46, 187-200.

MacLeod, Andrea A. N. \& Carol Stoel-Gammon. 2005. Are bilinguals different? What VOT tells us about simultaneous bilinguals. Journal of Multilingual Communication Disorders 3(2), 118-127.

MacLeod, Andrea A. N. \& Carol Stoel-Gammon. 2010. What is the impact of age of second language acquisition on the production of consonants and vowels among childhood bilinguals? International Journal of Bilingualism 14(4), 400-421.

Magloire, Joël \& Kerry P. Green. 1999. A cross-language comparison of speaking rate effects on the production of voice onset time in English and Spanish. Phonetica 56, 158-185.

Major, Roy. 1987. English voiceless stop production by speakers of Brazilian Portuguese. Journal of Phonetics 15, 197-202. 
Marian, Viorica, Henrike K. Blumenfeld \& Margarita Kaushanskaya. 2007. The language experience and proficiency questionnaire (LEAP-Q): Assessing language profiles in bilinguals and multilinguals. Journal of Speech, Language and Hearing Research 50, 940-967.

Marian, Viorica \& Michael Spivey. 2003a. Competing activation in bilingual language processing: Withinand between-language competition. Bilingualism: Language and Cognition 6, 97-115.

Marian, Viorica \& Michael Spivey. 2003b. Comparing bilingual and monolingual processing of competing lexical items. Applied Psycholinguistic 24, 173-193.

Meuter, Renata F. I. \& Alan Allport. 1999. Bilingual language switching in naming: Asymmetrical costs of language selection. Journal of Memory and Language 40, 25-40.

Myers-Scotton, Carol. 1993. Dueling languages. Oxford: Oxford University Press.

Nathan, Geoffrey S., Warren Anderson \& Budsaba Budsayamongkon. 1987. On the acquisition of aspiration. In Georgette Ioup \& Stephen Weinberger (eds.), Interlanguage phonology, 204-212. Rowley, MA: Newbury House.

Olson, Daniel J. 2013. Bilingual language switching and selection at the phonetic level: Asymmetrical transfer in VOT production. Journal of Phonetics 41, 407-420.

Olson, Daniel J. The impact of code-switching, language context, and language dominance on suprasegmental phonetics Evidence for the role of predictability. The International Journal of Bilingualism, doi: 10.1177/1367006914566204. Published by Sage, 4 February 2015.

Olson, Daniel J. The gradient effect of context on language switching and lexical access in bilingual production. Applied Psycholinguistics, doi:10.1017/S0142716415000223. Published online by Cambridge University Press, 20 July 2015.

Olson, Daniel J. \& Marta Ortega-Llebaria. 2010. The perceptual relevance of code-switching and intonation in creating narrow focus. In Marta Ortega-Llebaria (ed.), Selected proceedings of the 4th Conference on Laboratory Approaches to Spanish Phonology, 57-68. Sommerville, MA: Cascadilla Proceedings Project.

Pallier, Christophe, Laura Bosch \& Nuria Sebastian-Galles. 1997. A limit on behavioral plasticity in speech perception. Cognition 64, B9-B17.

Piccinini, Page \& Amalia Arvaniti. 2015. Voice onset time in Spanish-English spontaneous codeswitching. Journal of Phonetics 52, 121-137.

Poplack, Shana \& Gillian Sankoff. 1984. Borrowing: The synchrony of integration. Linguistics 22(1), 99-135.

R Core Development Team. 2008. R: A language and environment for statistical computing (version 3.0.2). Vienna: R Foundation for Statistical Computing. http://www.R-project.org (accessed 1 February 2014).

Simonet, Miquel. 2014. Phonetic consequences of dynamic cross-linguistic interference in proficient bilinguals. Journal of Phonetics 43, 26-37.

Soares, Carlos \& François Grosjean. 1984. Bilinguals in a monolingual and a bilingual speech mode: The effect on lexical access. Memory and Cognition 12, 380-386.

Spivey, Michael \& Viorica Marian. 1999. Cross talk between native and second languages: Partial activation of an irrelevant lexicon. Psychological Science 10(3), 281-284.

Volterra, Virginia \& Traute Taeschner. 1978. The acquisition and development of language by bilingual children. Journal of Child Language 5, 311-326.

Weber, Andrea \& Anne Cutler. 2004. Lexical competition in non-native spoken-word recognition. Journal of Memory and Language 50, 1-25.

Williams, Lee. 1977. The voicing contrast in Spanish. Journal of Phonetics 5(2), 169-184.

Zentella, Ana C. 1997. Growing up bilingual. Oxford: Blackwell. 